\title{
THE UNSUITABILITY OF POLYTHENE FOR MOVABLE WEIGHT-BEARING PROSTHESES
}

\author{
Report of a Case of Cup Arthroplasty of the Hip
}

\author{
P. H. Newmax and J. T. Scales, London, Exglaxd \\ From the Royal National Orthopaedic Hospital and the Plastic Research Cnit \\ of the Institute of Orthopaedics, London
}

This report deals with the use of polythene in a weight-bearing joint. In the case described a cup arthroplasty of the hip was performed. Clinically this was a failure, but it demonstrated the unsuitability of the material for any purpose where it is exposed to load and abrasive action at the same time.

\section{GHEMICAL AND PHYSICAL PROPERTIES OF POLYTHENE}

Polythene is a synthetic thermo-plastic material formed by the polymerisation of the gas ethylene $\left(\mathrm{C}_{2} \mathrm{H}_{4}\right)$. The polymer produced is a hydro-carbon of high molecular weight, belonging to the paraffin series, the carbon chain being 1,000 to 2,000 carbon atoms long. It has, therefore, the stability and high resistance to chemical change characteristic of ordinary paraffins, but at the same time possesses considerably better mechanical properties. Being a hydro-carbon it is insoluble in and not wetted by water or tissue fluids. It absorbs water very slightly but even after prolonged immersion gains less than 0.05 per cent in weight.

Polythene would seem to be an ideal material for implantation purposes in view of the above chemical properties. Animal experiments which we have carried out, and the findings of other investigators (Brown et al. 1947, Ingraham et al. 1947, Clagett et al. 1948, Donovan and Zimmermann 1949, Serbold et al. 1949, Grindlay and Mann 1948, Busch ct al. 1949, Condon and Harper 1949, Yeager and Cowley 1948) have encouraged us in this belief. Although mechanical properties were known to be short of the ideal, it was believed that they would be adequate to meet the demands of a cup arthroplasty of the hip.

During the first few weeks after such an operation the patient is not allowed to bear weight, and it was thought that once the acetabulum had become lined and the femoral head covered with fibrous tissue or fibrocartilage, the polythene would not then be exposed to the abrasive surfaces. By this time the complementary contours of the femoral head and the acetabulum would have been established and the cup would then be evenly supported on both sides and bearing only intermittent pressure. It was hoped that the resilience of polvthene might be an advantage over the rigidity of vitallium; this rigidity has been cited (Hernández-Ros and Codorníu 1949) as a cause of painful hips following vitallium cup arthroplasty owing to the concentration of pressure on a small area of bone. Vitallium cups are thin in cross section, and the lever of abduction of the hip joint is therefore reduced after removal of bone from the acetabulum and head of the femur. The polythene cup was thickened at its centre as a means of restoring the mechanical efficiency of the abduction lever.

Polythene is transparent to $\mathrm{X}$-rays and therefore the condition of the femoral head and acetabulum can be studied radiologically at any time-as with the acrylic cups of Harmon (1942) and of Hernández-Ros and Codorníu (1949).

The cup (Fig. 1) was turned from 3-inch diameter polythene rod, which had been specially prepared by the manufacturers of the material in order to ensure purity. The cup was polished by playing over both surfaces a stream of hot nitrogen issuing from the nozzle of a torch at a temperature of 300 degrees centigrade. (Some inert gas must be used for this 
purpose, for polythene readily oxidises when it is heated above 130 degrees centigrade in air.) Sterilization was carried out by boiling for half an hour on three consecutive dars. The dimensions of the cup were as follows:

Outside depth. . . 4.3 centimetres

Inside depth . . . $\quad 3 \cdot 4$ centimetres

Thickness of cup at apex . $\quad 0 \cdot 9$ centimetres

()utside diameter . . . $\quad 4 \cdot 5$ centimetres

Inside diameter . . 4.2 centimetres

IVall thickness of skirt $\quad 0 \cdot 3$ centimetres

A female reamer suitable for a $2 . \mathrm{L}$ Smith-Petersen cup was used to shape the femoral head and a male reamer suitable for a $3 . M$ cup for shaping the acetabulum.

\section{CASE HISTORY}

A patient was selected who needed a bilateral cup arthroplasty of the hips. A vitallium cup was inserted on one side and a polythene cup on the other in order to obtain a comparison between the two materials. The patient, a woman aged fifty-three years, had for nine years been suffering from gradually increasing pain, restriction of movement and instability of both hips. She had no fixed deformity in either hip, but movement was more restricted on the right sicle than on the left. Radiographs showed bilateral osteoarthritis with partial subluxation (Fig. 2). An arthroplasty of the left side was done, using a vitallium cup. Thirty-five days later an

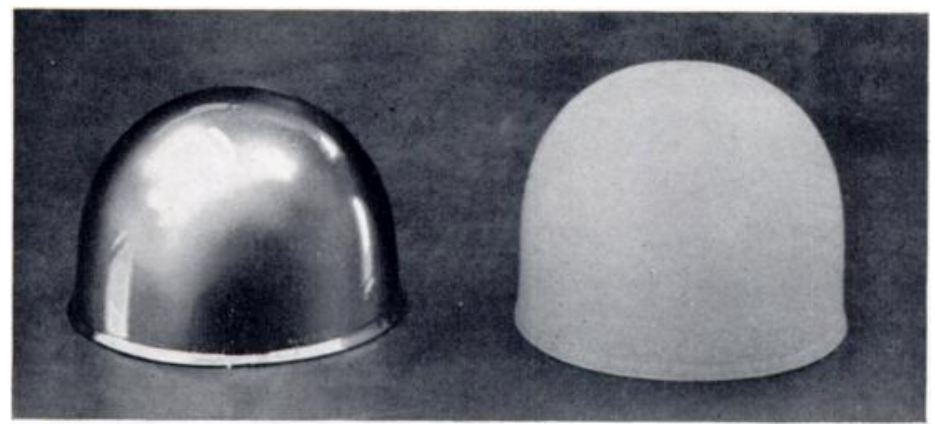

Fig. 1

Vitallium and polythene cups, showing difference in height.

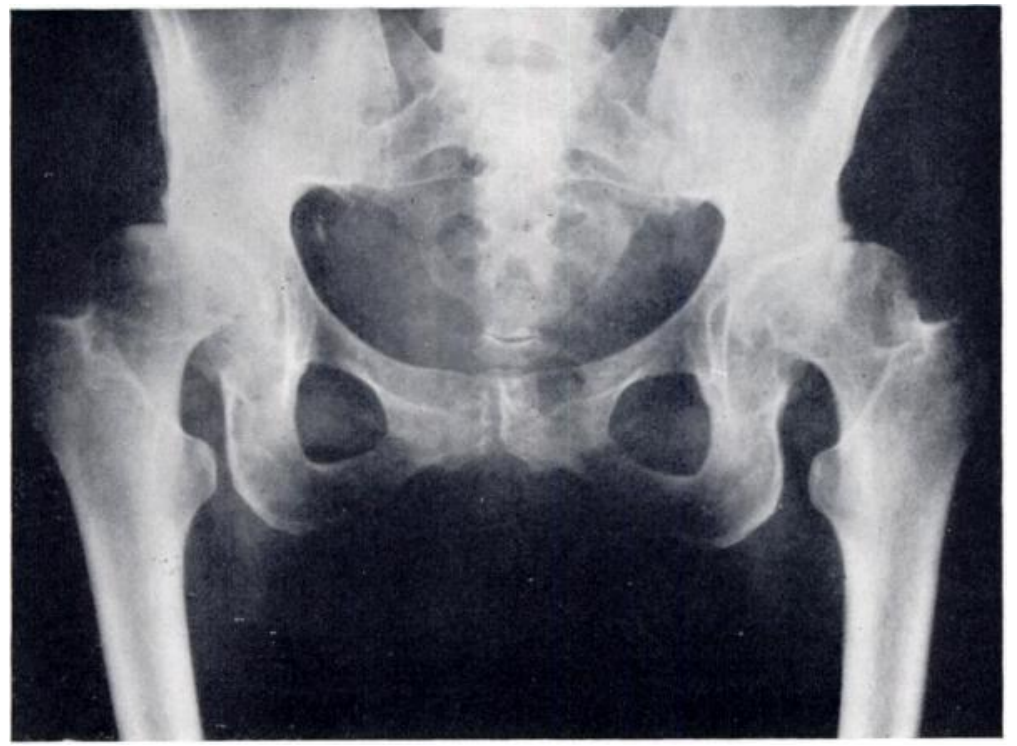

FIG. 2

Radiograph showing bilateral osteoarthritis following subluxation. 
arthroplasty was done on the right side, using a polythene cup. The limb was put on a Thomas's splint with $5 \mathrm{lb}$. below-knee skin traction. The incisions healed satisfactorily, but the patient complained of a slight ache in the right knee and a vague stiffness in the right hip. After two months the right hip was painful after moderate exercise in bed and there was a tendency to

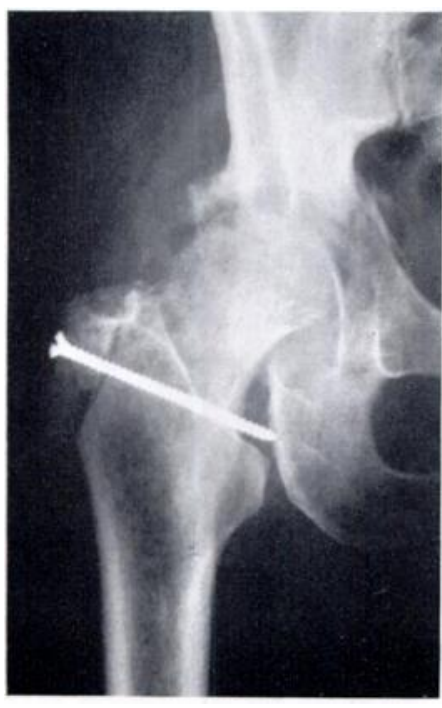

FIG. 3

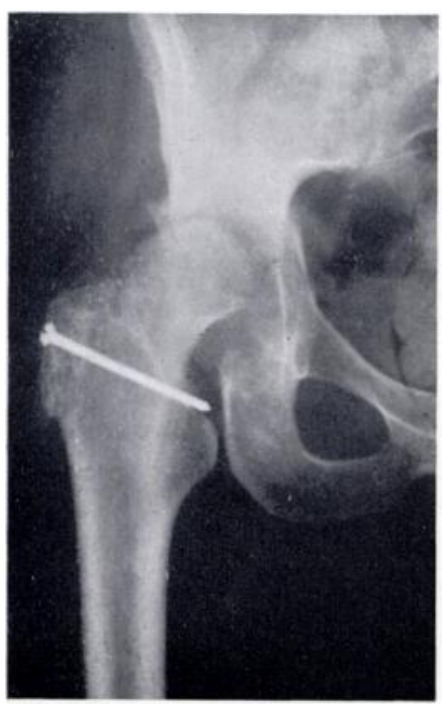

Fig. 4

Right hip with polythene cup in position. Figure 3-Three weeks after arthroplasty. Figure 4-Seven weeks after arthroplasty.

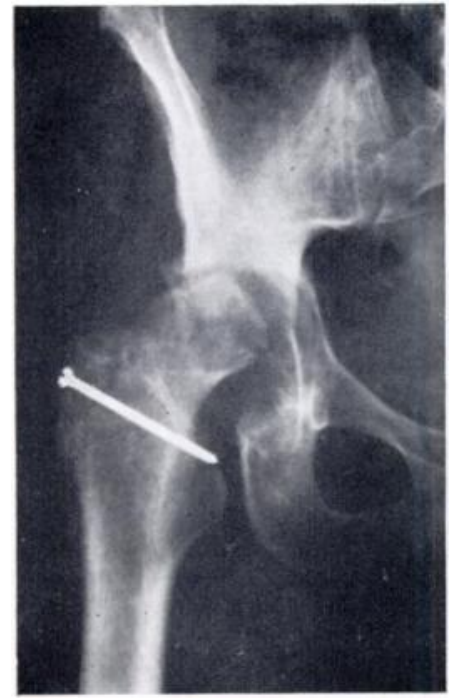

FIG. 5

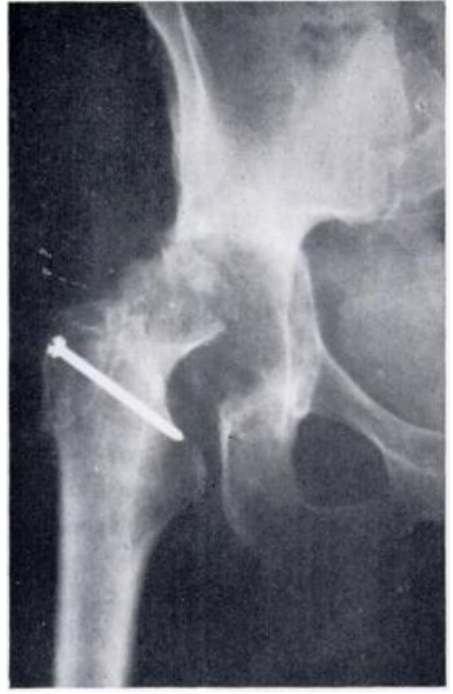

FIG. 6

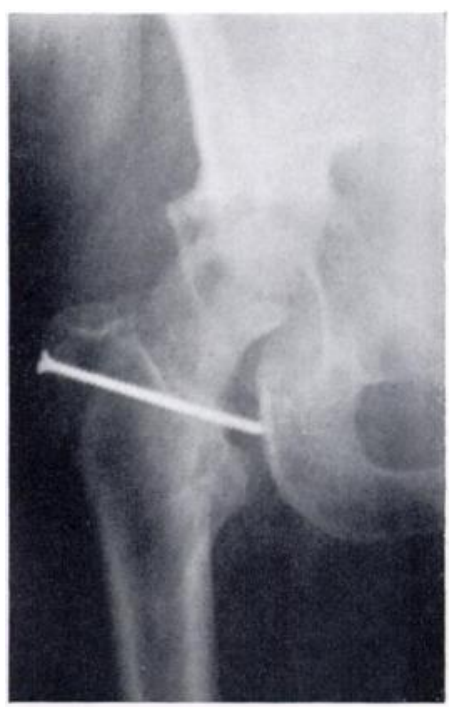

FIG. 7

Right hip. Figure 5-Ten weeks after arthroplasty. Figure 6-Thirteen weeks. Figure 7--Sixteen weeks.

lateral rotation. Weight-bearing was not allowed until four months after operation, when the patient was allowed to get up and bear weight in the swimming pool.

Figure 3 shows the condition three weeks after operation; the femoral head is smooth in outline. In Figure 4, seven weeks after the arthroplasty, the outline of the femoral head is becoming irregular and mottled, suggesting bone absorption. Subluxation is occurring. In Figure 5 , ten weeks after operation, subluxation has increased slightly but space, superiorly, due to 
the interposition of the polythene, is still visible. Figure 6 shows the hip twelve and a half weeks after operation. At this time the patient had been bearing weight in the swimming pool for approximately one and a half hours a day for nine days. Subluxation has increased further. There is no evidence of fusion but there has been further erosion of the femoral head. At this time there was increased pain in the right hip, and movements were becoming more restricted. At fifteen and a half weeks traction was reapplied and maintained for a further fourteen days. The subluxation was reduced but the joint space in the upper part had disappeared and there was practically no movement. The radiograph suggested that fusion was occurring and that the cup had worn through (Fig. 7). The hip was explored through the old scar. When the joint was opened a moderate amount of straw-coloured fluid welled out. The polythene cup was removed and was

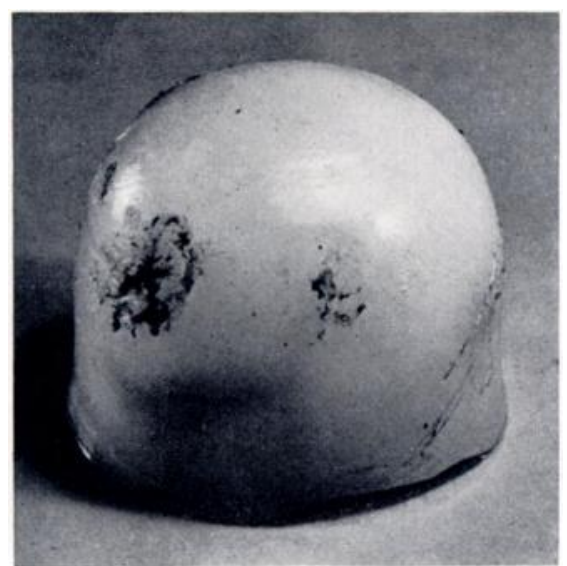

FIG. 8

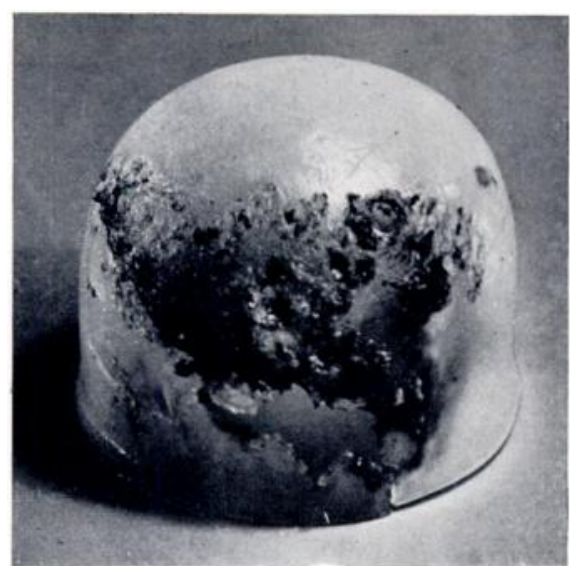

FIG. 9

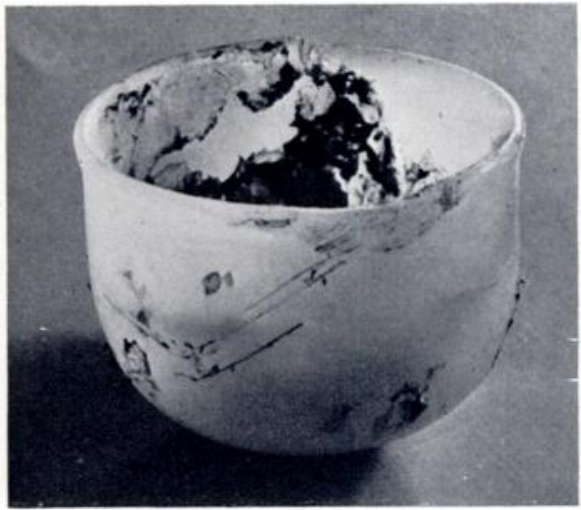

FIG. 10

Three views of the polythene cup after its removal. Figure 8-Lower surface. Figure $9-$ Upper surface. Figure 10-Inside of cup.

found to be eroded through in the weight-bearing area which, as can be seen from Figures 9 and 10, was in the lower part of the skirt of the cup. The acetabulum was lined with yellowish fibrous tissue about half a centimetre thick, the head of the femur being covered with a similar but thinner layer. A vitallium cup was inserted and the wound closed. The patient has made a satisfactory recovery.

A section of the material from the acetabulum is seen in Figures 11 and 12 . Figure 11 is a section viewed by normal transmitted light and it shows that the tissue consists of vascular granulation tissue containing many multinucleated foreign-body giant cells and a few inflammatory cells. The whole tissue, particularly the cytoplasm of the giant cells, is loaded with irregularly shaped fragments of the polythene. In Figure 12, which shows the same field under polarised light, the particles are very conspicuous because of their effect on the plane of polarised light.

vol. $33 \mathrm{~B}$, №. 3, AICGest 1951

$G_{i+1}$ 


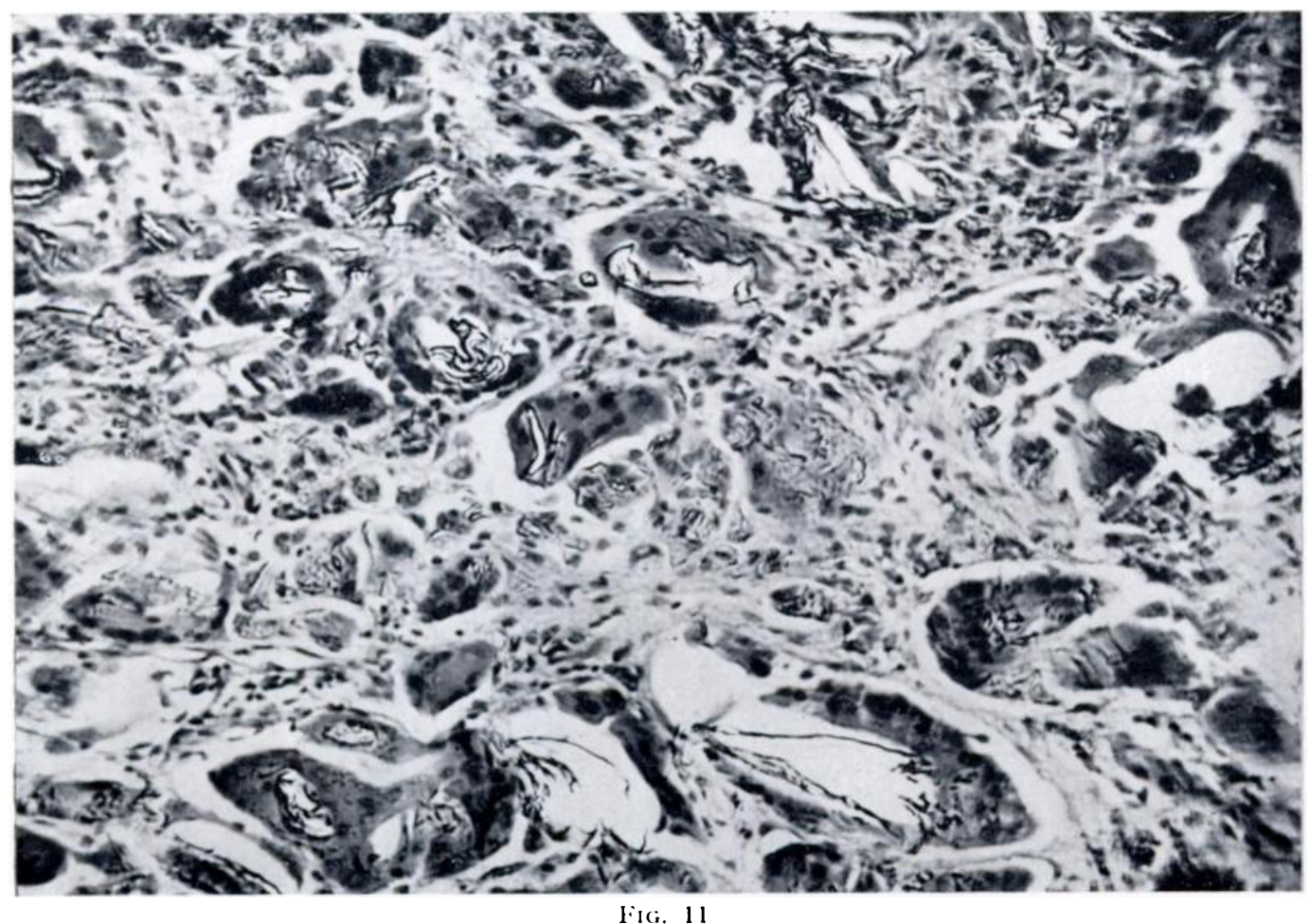

(iant cells with polythene nuclear bodies. There is considerable fibrous tissue reaction.

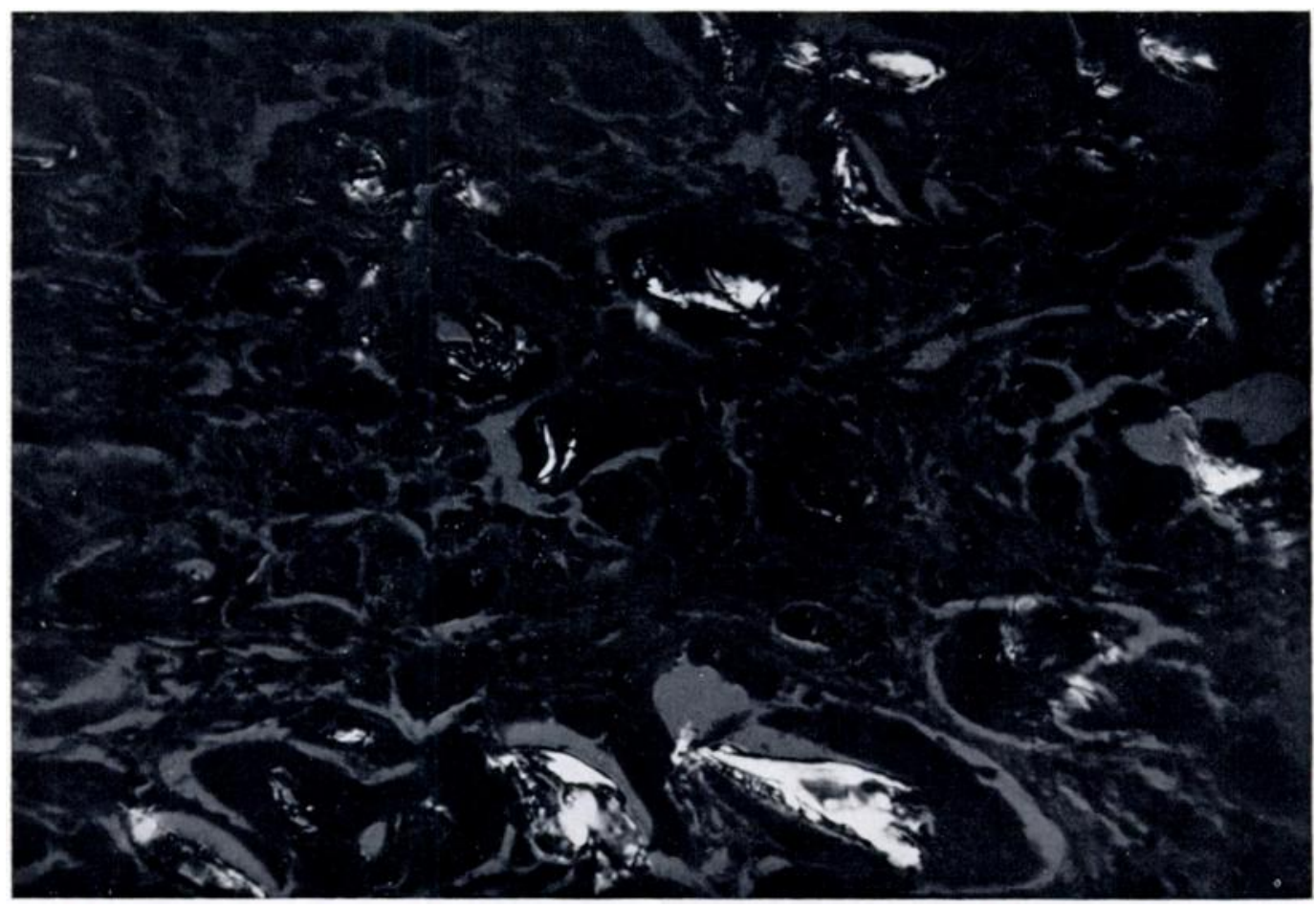

FIG. 12

The same field as that of Figure 11, viewed under polarised light. 


\section{DISCUSSION}

This case demonstrates that polythene, if used in a situation in which it is subjected to abrasion, will abrade; and that the particles so formed will stimulate a marked foreign body reaction, with giant-cell formation and fibrosis. From the literature and our own work on tissue reactions to polythene, it had been thought that this material wats inert when placed in the body. Figure 13 shows the result of the implantation of a piece of polvthene into the anterior abdominal wall of a guinea-pig. This material had been buried for seventy-two days. No foreign body giant cells are present and the fibrous tissue reaction is minimal. Although polythene is chemically inert, it appears, therefore, that the size and shape of the particles and the mechanical conditions in the tissues surrounding them play an important part in the production of tissue reactions. This case seems to support the views

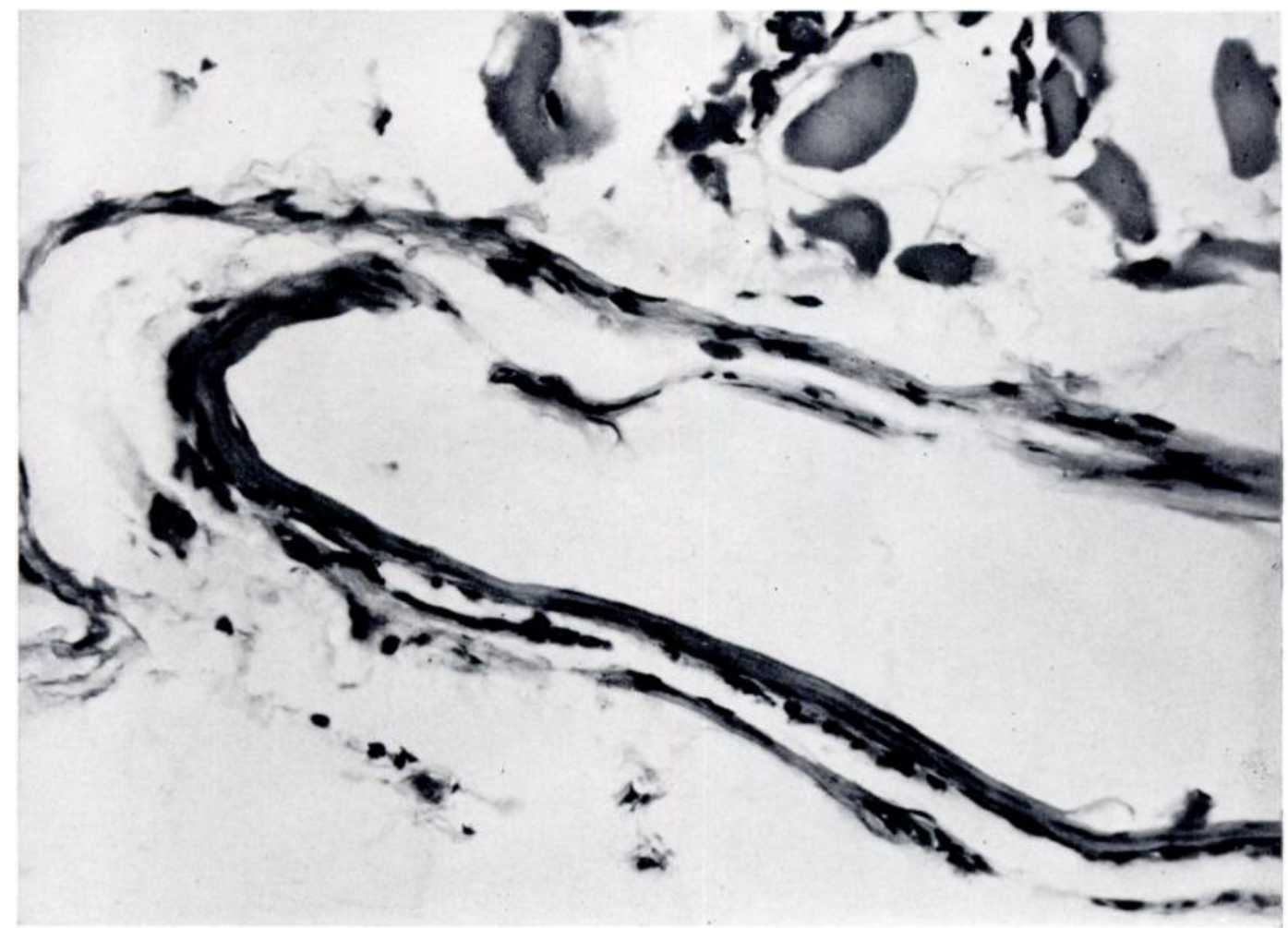

FIG. 13

Tissue reaction surrounding piece of half-round polythene approximately $11 \cdot 2$ inch.$(1 \cdot 1$ inch which hat been implanted for seventy-two days. Note minimal tissue reaction. (;.1'. $125(\cdot 9())$.

of Le Veen and Barberio (1949), who stated that attention should be paid not only to the chemical properties of the foreign substances implanted, but also to its physical characteristics . lior example, ferrous screws and plates were often used before the days of vitallium and there was often trouble from the galvanic effects that occurred when they were implanted in the body. With polythene galvanic effects do not play any part. The surface charge of foreign materials is also important, as well as the wettability of the material. Gortner and Briggs (1928) showed that there was a high electro-negative charge on the surface of glass in contact with water. When the glass was coated with paraffin, which cannot be wetted by water, the surface charge was zero. They postulated that the absorption of positively charged colloids in serum might explain the decreased clotting time in glass vessels as compared with paraffin-coated vessels. The surface charge of polvthene, which-like paraffin-cannot be

vol. $33 \mathrm{~B}$, No. 3, AcGe'st 1951

GI' 
wetted by water, is zero, and there is no absorption of colloids. It appears, therefore, that we are left with the size and shape of the particle as the cause of tissue reaction. The size of the polythene particles seen in the giant cells was less than 0.002 inches; larger particles did not appear to be ingested, but were encapsulated.

\section{SUMMARY}

In addition to its orthopaedic interest, this case illustrates the special behaviour of fine particles of a synthetic material when implanted in the human body. These results may interest those engaged in the control of dusts in the plastics industry, for the inhalation of such dusts may well result in "implantation" of the material in the lung, with consequent histological changes.

We wish to thank Dr H. A. Sissons of the Institute of Orthopaedics for his advice, Mr T. Fisher for his part in turning and polishing the cup, Mr S. Holt of Imperial (hemical Industries (Plastics Division) Ltd., who kindly made available the polythene for this work, and Mr R. J. W. Whitley for his photography.

\section{REFERENCES}

Brown, M. H., Grindlay, J. H., and Craig, W. M. (1947): Proceedings of the Staff Meetings of the Mayo Clinic, 22, 453.

Brown, M. H., Grindlay, J. H., and Craig, W. M. (1947): Journal of Neurosurgery, 4, 505.

Busch, E., Bing, J., and Hassen, E. H. (1949): Acta Chirurgica Scandinavica, 97, 410.

Clagett, O. T., Grindlay, J. H., and Moersch, H. J. (1948): Archives of Surgery, 57, 253.

Condon, W. B., and Harper, F. R. (1949): Archives of Surgery, 59, 705.

Donovas, T. J., and Zimmermans, B. (1949): Journal of Haematology, 4, 1310.

Gortser, R. A., and Briggs, D. R. (1928): Proceedings of the Society for Experimental Biology and Medicine, 25, 820.

Grindlay, J. H., and MaNn, F. C. (1948): Archives of Surgery, 56, 794.

Harmos, P. H. (1942): Guthrie Clinic Bulletin, 11, 124.

Hernández-ros y Codorít, A. (1949): Cirugia del Aparato Locomotor, 6, 11.

Ingraham, F. D., Alexander, E., and Matson, D. D. (1947): Journal of the American Medical Association, $135,82$.

Le Veen, H. H., and Barberio, R. J. (1949): Annals of Surgery, 120, 74.

Seybold, W. D., Grindlay, J. H., Pfeutze, K. H., and Clagett, O. T. (1949): Journal of Thoracic Surgery, 18, 129.

Yeager, G. H., and Cowley, R. A. (1948): Anales de Cirugia, 9, 509. 